\title{
QUANTIFICAÇÃO DE VARIÁVEIS LIMNOLÓGICAS EM UMA SEÇÃO TRANSVERSAL DO RIO CATOLÉ GRANDE, BA
}

Romário Oliveira de Santana ${ }^{1}$, Mayanna Silva Bessa Leite ${ }^{2}$, Lídia Raiza Sousa Lima Chaves Trindade ${ }^{3}$, Flávia Mariani Barros ${ }^{4}$, Danilo Paulúcio da Silva ${ }^{4}$

1. Mestrando em Ciências Ambientais da Universidade Estadual do Sudoeste da

Bahia, Itapetinga - Bahia, Brasil. (engenheiro.romario@hotmail.com)

2. Mestre em Ciências Ambientais da Universidade Estadual do Sudoeste da Bahia, Itapetinga - Bahia, Brasil.

3. Mestranda em Desenvolvimento e Meio Ambiente da Universidade Estadual de Santa Cruz, Ilhéus - Bahia, Brasil.

4.Professor Doutor da Universidade Estadual do Sudoeste da Bahia, Departamento de Ciências Exatas e Naturais, Itapetinga - Bahia.

Recebido em: 08/04/2017 - Aprovado em: 10/06/2017 - Publicado em: 20/06/2017 DOI: 10.18677/EnciBio_2017A116

Objetivou-se com o presente trabalho quantificar as variáveis limnológicas em uma seção transversal do rio Catolé Grande. As foram coletadas segundo a metodologia proposta pela NBR 9898/87, em diferentes meses. Nessas amostras foram realizadas análises de condutividade elétrica, oxigênio dissolvido, potencial hidrogeniônico $(\mathrm{pH})$, turbidez, sólidos totais, fixos e voláteis. Dentre as variáveis observadas $\mathrm{o} \mathrm{pH}$ e a turbidez apresentaram valores dentro do limite estabelecido pela Resolução CONAMA 357/2005 para rios de Classe 2. Dentre as coletas realizadas apenas a segunda apresentou valor de oxigênio dissolvido abaixo do limite estabelecido pela legislação, as outras duas campanhas apresentaram, resultados em acordo com os padrões. A CONAMA 357/2005 não estabelece valores para condutividade elétrica, mas comparando os resultados encontrados com a literatura, percebe-se no período de estudo ocorreu uma contribuição de nutrientes que podem ser provenientes de efluentes. Os sólidos fixos foram superiores aos voláteis em todas as campanhas de coleta o que indica uma maior contribuição de material de origem mineral.

PALAVRA-CHAVE: limnologia, monitoramento, recursos hídricos

\section{QUANTIFICATION OF LIMNOLOGICAL VARIABLES IN A CROSS SECTION OF CATOLÉ GRANDE RIVER, BA}

\footnotetext{
ABSTRACT

This study aimed to quantify the limnological variables in a cross section of the Catolé Grande river. The samples were collected according to the methodology proposed by NBR 9898/87, in different months. These samples were analyzed for 
electrical conductivity, dissolved oxygen, hydrogen ionic potential $(\mathrm{pH})$, turbidity, total solids, fixed and volatile. Among the observed variables, $\mathrm{pH}$ and turbidity presented values within the limit established by CONAMA Resolution 357/2005 for Class 2 rivers. Among the collected samples, only the second showed dissolved oxygen value below the limit established by the legislation, the other two campaigns presented results in accordance with the standards. The CONAMA 357/2005 does not establish values for electrical conductivity but comparing the results found on the literature, it is noticeable during the period of study a contribution of nutrients that may come from effluents occurred. Fixed solids were higher than volatiles in all collection campaigns indicating greater contribution of mineral material.

KEYWORDS: limnology, monitoring, water resources

\section{INTRODUÇÃO}

Segundo a Política Nacional de Recursos Hídricos (BRASIL, 1997) a gestão dos recursos hídricos deve assegurar o uso múltiplo das águas. Deste modo, os vários usos das águas devem possuir diferentes requisitos de qualidade. No que se refere às condições e padrões de qualidade das águas, a Resolução CONAMA357/05 considera ser a classificação das águas doces, salobras e salinas essencial à defesa de seus níveis de qualidade, avaliados por condições e padrões específicos, de modo a assegurar seus usos preponderantes.

Para melhorar a gestão dos corpos d'água vêm sendo estabelecidos programas de monitoramento de qualidade da água nas bacias hidrográficas. Esses programas são de extrema relevância, pois possibilitam o conhecimento da qualidade das águas e auxiliam nas tomadas de decisões. O conhecimento da qualidade pode ser representado por diversas variáveis limnológicas que traduzem as principais características de corpos d'água (BARRETO et al. 2014).

Essas variáveis se correlacionam com as mudanças ocorridas na bacia hidrográfica, sejam elas de origem antrópica ou natural. Considerando o fato de essas variáveis sofrerem contínuas alterações espaço-temporais e da instabilidade do ambiente aquático, é de suma importância à escolha da forma de amostragem que possa melhor caracterizar o corpo d'água (LEITE et al., 2016). Essa caracterização deve levar em consideração os padrões estabelecidos na legislação, principalmente aqueles estipulados na resolução CONAMA 357/05. Diante do exposto, o presente trabalho teve como objetivo a quantificação de variáveis limnológicas em uma seção transversal do rio Catolé Grande, localizado no município de Itapetinga.

\section{MATERIAL E MÉTODOS}

A área estudo foi a bacia hidrográfica do Rio Catolé Grande, localizado no município de Itapetinga, estado da Bahia. A bacia está contida entre os paralelos N: 8380000 - 8226000 e meridianos E: 300000 - 385000, considerando o sistema de projeção Universal Transversa de Mercator (UTM). A nascente do Rio Catolé localiza-se no planalto de Vitória da Conquista, com seção de controle a jusante do perímetro urbano de Itapetinga (Figura 1). 
FIGURA 1. Localização da bacia hidrográfica do rio Catolé Grande.

Quanto à vegetação local, apresenta os seguintes tipos: floresta estacional decidual e semidecidual, floresta ombrófila densa, floresta estacional e submontana. A região situa-se em uma faixa de transição entre os ecossistemas da Mata Atlântica e da Caatinga. Sendo o clima predominantemente do tipo AW 19 (clima tropical com estação seca de inverno), além dos tipos Am (clima de monção) e BSh (clima das estepes quentes de baixa latitude e altitude) (AGROSSISTEMAS, 1976).

As coletas foram realizadas em uma seção localizada à montante da área urbana do município de Itapetinga, onde não há contaminação por fontes pontuais de poluição hídrica. Foram realizadas três coletas, durante o período de 11 de novembro de 2013, 09 de dezembro de 2013 e 14 de janeiro de 2014.

A coleta foi realizada de 15 a $30 \mathrm{~cm}$ de profundidade em relação a superfície, a amostra foi do tipo integrada, composta por amostras da margem direita, centro e margem esquerda da seção em estudo, aplicando-se os procedimentos de coleta recomendados pela NBR 9898 (ABNT, 1987), onde ressalta-se que com uma das mãos deve-se segurar o frasco pela base, mergulhando-o rapidamente com a boca para baixo, a cerca de 15 a $30 \mathrm{~cm}$ abaixo da superfície da água, para evitar a introdução de contaminantes superficiais, em seguida direcionou-se o frasco de modo que a boca ficasse em sentido contrário à corrente.

Após a coleta, as amostras de água foram acondicionadas em caixas de isopor e transportadas ao Laboratório de Solos da Universidade Estadual do Sudoeste da Bahia - Campus Itapetinga. Em cada amostra coletada, as variáveis físico-químicas foram quantificadas segundo metodologias descritas em MATOS (2012). 
Para determinação do $\mathrm{pH}$, foi empregado o método eletrométrico, com peagâmetro marca Digimed, modelo DM - 22. A condutividade elétrica foi alcançada através do condutivímetro marca Digimed, modelo DM - 32. A variável turbidez foi obtida pelo método nefelométrico, por meio do turbidímetro, Marca Digimed, modelo DM-TU - 0 a 1000 UNT. As concentrações de oxigênio dissolvido foram determinadas pelo método químico de Winkler, modificado pela ázida de sódio, que abrange diversas fases. A determinação das concentrações de sólidos totais, fixos e voláteis foi utilizado o método gravimétrico.

De acordo com o artigo 42 da Resolução CONAMA 357/2005 (BRASIL, 2005) enquanto não aprovado o enquadramento o corpo d'água de águas doces são consideradas classe 2. Desta forma, os resultados encontrados nas coletas foram comparados com os padrões da qualidade para classe 2 da Resolução CONAMA 357.

\section{RESULTADOS E DISCUSSÃO}

Os valores das variáveis limnológicas na seção transversal do rio Catolé Grande utilizando metodologia recomendada na NBR 9897/87 estão apresentados na Tabela 1. Os valores para turbidez apresentaram uma variação entre 5,28 a 33,97 NTU. Mesmo com o ocorrido os valores estiveram abaixo de 100 UNT, valor recomendado na Resolução CONAMA 357/2005 (BRASIL, 2005) para água doce classe 2.

As coletas 1 e 2 apresentaram valores de turbidez superiores ao econtrado na coleta 3. Uma possível explicação para os valores encontrados seria o despejo de efluentes localizados próximos a esses pontos ou por precipitações ocorridas na região que contribuiram para o aumento do escoamento e com isso aumentando a concentração de partículas na época de estudo.

TABELA 1: Valores das variáveis limnológicas em diferentes épocas em uma seção transversal do rio Catolé Grande.

\begin{tabular}{|c|c|c|c|c|c|c|c|}
\hline Coletas & $\begin{array}{c}\text { Turbidez } \\
\text { (NTU) }\end{array}$ & $\begin{array}{c}\text { CE* }^{\star} \\
(\mu \mathrm{S} / \mathrm{cm})\end{array}$ & pH & $\begin{array}{c}\mathrm{OD}^{\star \star} \\
(\mathrm{mg} / \mathrm{L})\end{array}$ & $\begin{array}{c}\mathrm{ST}^{\star \star \star} \\
(\mathrm{mg} / \mathrm{L})\end{array}$ & $\begin{array}{l}\text { SF**** } \\
(\mathrm{mg} / \mathrm{L})\end{array}$ & $\begin{array}{l}\mathrm{SV}^{\star * \star \star *} \\
(\mathrm{mg} / \mathrm{L})\end{array}$ \\
\hline $11 / 11 / 2013$ & 33,97 & 108,21 & 7,74 & 5,25 & 97,00 & 53,33 & 43,67 \\
\hline $09 / 12 / 2013$ & 29,33 & 118,50 & 7,76 & 4,77 & 129,33 & 99,00 & 30,33 \\
\hline $14 / 01 / 2014$ & 5,28 & 158,22 & 7,42 & 5,43 & 174,67 & 104,67 & 70,00 \\
\hline
\end{tabular}

DONADIO et al. (2005), verificando a influência dos diferentes usos do solo nas variáveis de qualidade da água em nascentes da bacia do Córrego Rico, encontraram valores de turbidez entre 2,4 e 7,9 NTU para nascentes com vegetação natural remanescente e valores entre 12,2 e 26,1 NTU para nascentes com a presença de uso agrícola. Esses valores corroboram com os encontrados no presente estudo e indica que a seção do rio Catolé Grande tem sofrido interferências antrópicas, principalmente com agricultura e pecuária. Segundo BARRETO et al. (2014), a bacia do rio Catolé Grande apresenta seu uso e ocupação do quase que restritamente voltado para agropecuária.

MARMONTEL \& RODRIGUES (2015), realizando uma avaliação qualitativa em nascentes com diferentes coberturas do solo e conservação da vegetação em seu entorno, encontraram valores de turbidez entre 12,6 e 173,6 UNT. Segundo os 
autores cursos d'água com valores de turbidez superior ao estabelecido na legislação evidenciam a degradação devido ao despejo de efluentes, acesso de animais ao olho d'água e ausência de mata ciliar.

A Resolução CONAMA 357/2005 (BRASIL, 2005) não estabelece valores mínimos e/ou máximos para condutividade elétrica então nesse caso utiliza-se o valor determinado pela CETESB (2013), que é $100 \mu \mathrm{S} / \mathrm{cm}$, sendo considerados como ambientes impactados os corpos d'água com condutividade elétrica acima desse valor.

Os valores para CE nas campanhas de coleta ficaram entre 108,21 e 158,22 $\mu \mathrm{S} / \mathrm{cm}$, não estando de acordo com os padrões estabelecidos, o que indica que a área de estudo tenha recebido cargas de efluentes e um aporte de nutrientes do solo, e com isso ocasionado uma elevação da condutividade elétrica. Segundo SANTOS et al. (2013), a variação sazonal da precipitação é outro fator que pode ocasionar o aumento nos valores de condutividade, pois com a chuva ocorre a lixiviação de alguns nutrientes para os cursos d'água.

MORAES et al. (2015), observaram uma variação da condutividade elétrica entre 120,42 e 145,36 $\mathrm{\mu S} / \mathrm{cm}$ para o rio Catolé Grande, o que corrobora com os resultados do presente trabalho. Segundo os autores, os valores encontrados podem está associados ao lançamento de elfuentes domésticos e industrias no corpo hídrico. De acordo com KUHNEN et al. (2016), valores elevados de condutividade elétrica indicam elevada quantidade de matéria orgânica em decomposição.

Os valores para o potencial hidrogeniônico apresentaram uma pequena variação entre 7,42 e 7,76, indicando valores aceitáveis de acordo com 0 recomendado na Resolução CONAMA 357/2005 (BRASIL, 2005). De acordo com VON SPERLING (2014), a elevação do potencial hidrogeniônico em ambientes aquáticos pode ser relacionada com as características geológicas da área, despejos domésticos e industriais de efluentes e/ou à presença de plantas aquáticas. $O$ aumento do pH também pode ocorrer devido à mineralização do material orgânico do meio. MORAES et al. (2015) avaliando a qualidade da água no rio Catolé Grande, observaram uma variação do pH entre 7,38 e 8,64.

A concentração de OD é a mais importante, pois ela é capaz de expressar a qualidade do ambiente aquático (VON SPERLING, 2014). Nos corpos d'água a dissolução do oxigênio atmosférico e produção por plantas aquáticas são as principais fontes de oxigênio dissolvido (BARROS et al., 2013). Sendo que o lançamento de esgoto doméstico e resíduos sólidos pode afetar diretamente a disponibilidade de oxigênio dissolvido na água. (SANTOS et al., 2013).

O OD neste estudo variou de 4,77 a 5,43 mg/L. Apenas o valor de OD da segunda coleta estava abaixo do estabelecido pela Resolução CONAMA 357/2005 (BRASIL, 2005), a qual determina que os valores de OD para águas doce classe 2 não devem ser inferiores a $5 \mathrm{mg} / \mathrm{L}$ de $\mathrm{O}_{2}$. De acordo com o artigo 42 da Resolução CONAMA 357/2005 (BRASIL, 2005), corpos de água doce como o rio Catolé que não passaram pelo enquadramento devem adotar os padrões estabelecidos para as águas doces Classe 2.

MORAES et al. (2015), analisando parâmetros físico-químicos no mesmo rio, encontraram valores de OD entre 1,65 e $6,18 \mathrm{mg} / \mathrm{L}$. Segundo os autores os valores de oxigênio dissolvido abaixo de do estabelecido pela legislação são ocasionados devido a contribuição da matéria orgânica nos efluentes lançados no rio. 
TRINDADE et al. (2016) analisando a espacialização do oxigênio dissolvido na Lagoa do Parque Poliesportivo de Itapetinga, encontraram valores de oxigênio dissolvido entre 4,47 a $6,15 \mathrm{mg} / \mathrm{L}$. Segundo os autores os valores abaixo de $5 \mathrm{mg} / \mathrm{L}$ indicam grande impacto neste ambiente, além do lançamento de esgoto doméstico e resíduos sólidos por estabelecimentos próximos ao local.

Os valores de ST variaram entre 97,00 e $174,67 \mathrm{mg} / \mathrm{L}$. As resoluções CONAMA 357/05 e 430/11 não estabelecem valores para as concentrações de ST. Em rios processos de erosão nas margens e lançamentos de efluentes são os principais responsáveis pelo aumento de sólidos na água.

Analisando o mesmo rio GENEROSO et al. (2010), encontraram uma variação da concentração de ST entre 16 e $79 \mathrm{mg} \mathrm{L}^{-1}$, resultados estes inferiores ao encontrado no presente estudo. Esses resultados indicam que no período de estudo ocorreu uma maior contribuição de partículas sólidas.

As concentrações de SF variaram entre 53,33 e $104,67 \mathrm{mg} / \mathrm{L}$, já os valores de SV ficaram entre 43,67 e $70,00 \mathrm{mg} / \mathrm{L}$. Em todas as coletas analisadas a concentração de sólidos fixos foi superior a sólidos voláteis o que indica uma maior presença de matéria de origem mineral. Determinar a concentração de sólidos é de grande importância principalmente para tratamento de efluentes, pois dependendo do tipo será escolhido o melhor de tratamento a ser utilizado.

\section{CONCLUSÃO}

A turbidez apresentou uma variação entre 5,28 e 33,97 NTU, logo estão dentro do estabelecido pela legislação para corpos d'água doce classe II. A condutividade elétrica apresentou valores entre 108,21 e 158,22 $\mu \mathrm{S} / \mathrm{cm}$ o que indica inconformidade com o recomendado pela CETESB (2013). Os valores de oxigênio dissolvido observado neste estudo tiveram pouca variação $(4,77$ a $5,43 \mathrm{mg} / \mathrm{L})$. A segunda coleta foi a única que apresentou valor abaixo do estabelecido pela Resolução CONAMA 357/2005 (BRASIL, 2005) para rios classe 2. Os valores observados para $\mathrm{pH}$ apresentaram amplitude média pequena variando entre 7,42 e 7,76. Os sólidos totais para seção do rio Catolé Grande variaram entre 97,00 e $174,67 \mathrm{mg} / \mathrm{L}$. Os valores de sólidos fixos foram superiores aos sólidos voláteis o que indica uma presença maior de material de origem mineral.

\section{REFERÊNCIAS}

AGROSSISTEMAS pastoris In: Diagnóstico socioeconômico da região cacaueira: dinâmica do uso da terra. v3 CEPLAC- MA IICA: Bahia: 1976.

ABNT - Associação Brasileira de Normas Técnicas. NBR 9898: preservação e técnicas de amostragem de efluentes líquidos e corpos receptores - Procedimento. Rio de Janeiro, 1987.

BARRETO, L. V.; FRAGA, M. S.; BARROS, F. M.; ROCHA, F. A. ; AMORIM, J. S.; DE CARVALHO, S. R.; BONOMO, P.; DA SILVA, D. P.. Relação entre vazão e qualidade da água em uma seção de rio. Revista Ambiente \& Água, v. 9, p. 118129, 2014. Disponível em: http://dx.doi.org/10.4136/ambi-agua.1278.

BARROS, F. M.; ROCHA, F. A.; FRAGA, M. S.; GENEROSO, T. N.; MELO A. R. B. $D E$. Variação da turbidez em pontos distintos de um perfil transversal do rio Catolé, 
BA, sob diferentes níveis de vazão. Enciclopédia Biosfera, v. 7, p. 1-6, 2013. Disponível em: < http://www.conhecer.org.br/enciclop/2011a/agrarias/variacao\%20da\%20turbidez.pdf $>$

BRASIL. Lei $n .^{\circ}$ 9433, de 8 de janeiro de 1997. Institui a Política Nacional de Recursos Hídricos, cria o Sistema Nacional de Gerenciamento de Recursos Hídricos. Regulamentou o artigo 21, inciso XIX da Constituição Federal.

BRASIL 2005. Resolução CONAMA (Conselho Nacional de Meio Ambiente). Resolução n.. 357, de 17 de março de 2005. Diário Oficial da República Federativa do Brasil, Brasília, 2005.

CETESB (Companhia de Tecnologia de Saneamento Ambiental). Relatório de qualidade das águas interiores do Estado de São Paulo 2009/CETESB. Significado ambiental e sanitário das variáveis de qualidade das águas e dos sedimentos e metodologias analíticas e de amostragem. São Paulo: CETESB, p. 4, 2013.

DONADIO, N. M. M.; GALBIATTI, J. A.; PAULA, R. DE. Qualidade da água de nascentes com diferentes usos do solo na Bacia Hidrográfica do Córrego Rico, São Paulo, Brasil. Revista de Engenharia Agrícola, Jaboticabal, v. 25, n.1, p. 115-125, 2005. Disponível em: < http://www.scielo.br/pdf/eagri/v25n1/24877.pdf>

GENEROSO, T. N.; FRAGA, D. S.; TAGLIAFERRI, C.; ROSA, R. C. C. Influência do local de amostragem nos valores de variáveis de qualidade de água em uma seção transversal do rio Catolé - BA. Enciclopédia Biosfera, Goiânia, v.6, n.11, 2010. Disponível em:

http://www.conhecer.org.br/enciclop/2010c/influencia\%20do\%20local.pdf>

KUHNEN, A. R.; ARAUJO, G. M.; BARBOSA, W. W. P. Aquaponia como alternativa para o cultivo de peixes e Hortaliças . In: XIV Encontro Nacional de Estudantes de Engenharia Ambiental, 2016, Brasília. Anais do XIV ENEEAmb, 2016. Disponível em: < http://dx.doi.org/10.5151/engpro-eneeamb2016-rh-004-4914>

LEITE, M. S. B.; BARROS, F. M.; DA SILVA, D. P.; DE SANTANA, R. O.; AMORIM, J. S.; DE CARVALHO, S. R. Comparação entre metodologias de amostragem de água para quantificação de variáveis limnológicas em ambiente lótico. Revista Ambiente \& Água, v. 12, p. 136-145, 2016. Disponível em: < http://dx.doi.org/10.4136/ambi-agua.1781>

MARMONTEL, C. V. F.; A. Avaliação qualitativa de nascentes com diferentes coberturas do solo e conservação da vegetação em seu entorno no córrego Pimenta. Scientia Agraria Paranaensis, v. 14, p. 53-59, 2015. Disponível em: < http://dx.doi.org/10.18188/1983-1471/sap.v14n1p53-59>

MATOS, A.T.; Qualidade do Meio Físico Ambiental: Práticas de Laboratório. 1. Ed. Viçosa, MG. Editora UFV. 2012. 150p. 
MORAES, C. A. C.; LIMA, J. L. R.; COSTA, C. L. S.; SANTANA, R. O.; BARROS, F. M. Avaliação espacial da qualidade da água do rio catolé grande. Enciclopédia Biosfera, v. 11 p. 471-478, 2015. Disponível em: < http://dx.doi.org/10.18677/Enciclopedia_Biosfera_2015_100>

SANTOS, Q. R.; FRAGA, M. S.; ULIANA, E. M.; REIS, A. S.; M. Monitoramento da qualidade da água em uma seção transversal do rio Catolé, Itapetinga-BA. Enciclopédia Biosfera, v. 9, p. 1503-1519, 2013. Disponível em: http://www.conhecer.org.br/enciclop/2013a/agrarias/Monitoramento\%20da\%20Quali dade.pdf

TRINDADE, L. R. S. L. C.; SANTANA, R. O.; SANTOS, A. S.; BARROS, F. M. Variação Espacial da Qualidade da Água na Lagoa do Parque Poliesportivo de Itapetinga, Bahia. In: Giovanni Seabra. (Org.). Educação Ambiental e Biogeografia. 1ed.João Pessoa: Editoria Universitária - UFPB, 2016, v. 5, p. 452-462.

VON SPERLING, M. V. Introdução a qualidade das águas e ao tratamento de esgotos. Departamento de engenharia sanitária e ambiental, universidade federal de Minas Gerais - BH.4 ed. p. 107, 2014. 